\title{
400 ANOS DO DE LEGIBUS DE FRANCISCO SUAREZ (1548-1617)
}

\author{
400TH YEARS OF “DE LEGIBUS” BY FRANCISCO SUAREZ (1548-1617)
}

Paulo Borba Casella*

\begin{abstract}
Resumo:
O artigo destaca a importância da contribuição de Francisco SUAREZ (15481617) para a evolução do direito internacional, com ênfase nas questões práticas que este teve de enfrentar para formular soluções legais - o dado central da obra é a afirmação da unidade intrínseca da humanidade, em comunidade internacional formando um todo, apesar de dividida em povos e reinos. Observa o caráter de continuidade histórica entre o legado medieval e o Direito Internacional moderno, do qual o tratado Das leis e Deus legislador (1612) foi marco relevante.

Palavras-chave: Direito internacional - perspectiva histórica. Suarez tratado Das leis e Deus legislador (1612). Contribuição de Francisco Suarez (1548-1617) para a evolução do direito internacional. 400 anos da publicação do seu tratado De Legibus ac Deo legislator.
\end{abstract}

\begin{abstract}
:
The paper stresses the importance of the contribution of Francisco SUAREZ (15481617) for the evolution of international law, with emphasis in practical issues that he had to cope with, in order to provide legal solutions - the central feature of the work is the statement of the intrinsic unity of mankind, forming a whole, albeit divided in peoples and reigns. Observes the historical continuity from the medieval legacy towards modern international law, of which the treaty De Legibus ac Deo legislatore(1612) was a relevant landmark.
\end{abstract}

Keywords: International law - historical perspective. Suarez treaty De Legibus ac Deo legislatore (1612). Contribution of Francisco Suarez (1548-1617) for the evolution of international law. 400 years of the publication of his treaty.

O diálogo com as fontes, como caminho útil para a compreensão do conteúdo e do papel que tem a desempenhar o direito internacional em nosso tempo, foi proposto por Erik Jayme. ${ }^{1}$ Este modelo pós-moderno é frequentemente reproduzido

\footnotetext{
Professor Titular de Direito Internacional Público e vice-diretor da Faculdade de Direito da Universidade de São Paulo.

1 Sobre a relevância e o caráter inovador da contribuição de Erik Jayme para o Direito Internacional Privado, e a aplicação de seu modelo conceitual ao Direito Internacional Público, ver CASELLA, Paulo Borba. Fundamentos do direito internacional pós-moderno. Prólogo de Hugo Caminos. São Paulo: Quartier Latin, 2008.
} 
sem indicação da autoria da concepção. ${ }^{2}$ Bem mostra Erik Jayme $(1995)^{3}$ o caráter de mudança, de crise, de variabilidade de nosso tempo e de nosso direito.

Podem nesse sentido de 'diálogo com as fontes' ser resgatadas a figura e a contribuição de Francisco Suarez, como dados cruciais para a compreensão da evolução do direito internacional. Suarez se inscreve, na história do direito internacional, na passagem de seu legado medieval, para a concepção moderna deste. ${ }^{4}$

Não por acaso, ao se comemorarem 400 anos, desde a publicação do tratado de Suarez sobre as leis, nos surpreende a atualidade da sua mensagem e a utilidade de conhecer alguns conceitos básicos de sua obra. Não somente pelo interesse 'histórico', do 'passado', mas como fonte, com a qual temos de dialogar, para entender e situar a evolução e as mutações do direito internacional, enquanto sistema institucional e normativo, desde fases anteriores até nosso contexto pós-moderno. ${ }^{5}$

Internacionalista, mas, sobretudo, teólogo, filósofo e autor de sistema, de alcance quase enciclopédico, contido em seu tratado sobre as leis e Deus legislador, De Legibus ac Deo legislatore (originalmente publicado em Coimbra, em 1612), Francisco Suarez, foi professor de grande renome, que ensinou filosofia e teologia nas universidades de Alcalá, Madri, Roma, Salamanca e Coimbra, como também em Paris. ${ }^{6}$ Grande personalidade do seu tempo, Suarez foi comentador das obras de Santo Tomás de Aquino, e também autor de diversas obras, ${ }^{7}$ com destaque para as obras nas quais trata de direito internacional.

2 Mas merece seja reconhecida a autoria da concepção do diálogo com as fontes a Erik JAYME, que a formulou em relação ao direito internacional privado, desde os anos 1980 e 1990. Em minha tese de titularidade, Fundamentos do direito internacional pós-moderno (2006; defendida em 2007; publicada em 2008) procurei estender ao direito internacional público esse exame pós-moderno.

3 JAYME, Erik. Identité culturelle et intégration: le droit international privé postmoderne: cours général de droit international privé. Recueil des Cours de L'Académie de Droit International, 1995, t. 251, p. 9-268) "avant-propos: explication du titre": "Nous assistons en effet au développement de deux tendances opposées : la première vise à favoriser de plus en plus le rapprochement des États au sein des marchés uniques, dans l'objectif d'améliorer le bien-être économique des différentes sociétés. La seconde tendance, dont le moteur est la réalité de l'identité culturelle des personnes qui sont unies par une tradition commune, conduit à la fragmentation des grands États pour donner naissance à de nouvelles nations indépendantes"; ver tb. JAYME, Erik. Considérations historiques et actuelles sur la codification du droit international privé. Recueil des Cours de L'Académie de Droit International, 1982, t. 177, p. 9-102.

4 A respeito, ver CASELLA, Paulo Borba. Direito internacional no tempo moderno - de SUAREZ a GRÓCIO e PUFENDORF. São Paulo: Atlas, 2013, esp. cap. XV sobre Francisco SUAREZ.

5 Ver CASELLA, P. B. Direito internacional no tempo antigo. São Paulo: Atlas, 2012, esp. capítulo I, 'questão e discurso do fundamento do direito internacional'; CASELLA, P. B. Direito internacional no tempo medieval e moderno até Vitória. São Paulo: Atlas, 2012.

6 BARCIA-TRELLES, C. Francisco Suarez (1548-1617): les théologiens espagnols du XVI ${ }^{\mathrm{e}}$. siècle et l'école moderne du droit international. Recueil des Cours de L'Académie de Droit International, 1933, t. 43, p. 385554; ROTHSTEIN, Marian (Ed.). Charting change in France around 1540. Selingsgrove: Susquehanna University Press, 2006; CALVINO, Oeuvres. Éd. établie par Francis Higman et Bernard Roussel. Paris: Gallimard - Pleïade, 2009.

7 VILLEY, Michel. A formação do pensamento jurídico moderno. (do original La formation de la pensée juridique moderne) Paris: PUF, 2003. trad. Claudia BERLINER, notas revistas por Eric DEMMONS, rev. 
Dentre estas, justamente seu tratado em "dez livros" - e em vários tomos -, sobre as leis, De legibus ac Deo legislatore (1612) se destaca como a sua contribuição principal, para a história das ideias. Mas, do conjunto dessa vasta e complexa obra interessam também, para o conhecimento das concepções jurídicas de Suarez: seu opúsculo sobre "a justiça de Deus"; seus três tratados relativos às "três virtudes teologais", especialmente no tratado sobre a caridade, De charitate, que contém relevante capítulo sobre o regime jurídico da guerra. ${ }^{8}$

Suarez também deixou outras obras filosóficas, tais como os seus comentários sobre diversas obras de Aristóteles, bem como a sua famosa obra de metafísica, Disputationes metaphysicae. Dentre as suas obras a respeito de polêmicas de seu tempo, teve especial destaque a defesa da fé católica contra os erros da seita anglicana, Defensio fidei (1613) dirigida contra o rei da Inglaterra, James I. Suscitou esta tal reação a ponto de ser condenada e queimada em praça pública - barbaridades que continuam a ser cometidas, ainda muito próximo de nós. A feroz reação contra a obra de Suarez, tanto em Paris, como em Londres, se deu em razão do fato deste defender a 'soberania popular', e inclusive o direito dos súditos de se rebelarem contra os desmandos de tiranos.

Suarez ainda deixou as obras de direito canônico, De censuris - sobre as penas eclesiásticas; bem como obra sobre as imunidades eclesiásticas, De immunitate ecclesiae; e, finalmente, seus Consilia, hoje diríamos, 'pareceres', nos quais se volta para questões jurídicas, morais etc. Como teólogo, tinha Suarez o papel de aconselhar e orientar a consciência e a conduta de seus príncipes. E isso adquire especial destaque, em razão da condição da Espanha, como potência dominante da Europa, na época. Em relação aos 'assuntos internacionais'.

A necessidade da perspectiva histórica na compreensão do direito internacional é óbvia e fundamental: este não é somente aparato técnico, mas também bagagem cultural. E como fenômeno cultural é preciso considerar o direito internacional, para que este possa ser adequadamente compreendido.

Querer dissociar o direito internacional do contexto histórico e cultural no qual se inscreve, não somente é reducionista, como impede compreender adequadamente

técnica Guido S. L. RIOS, texto estabelecido revisto e apresentado por Stéphane RIALS, São Paulo: WMF Martins Fontes, 2. ed., 2009. p. 347): “que SUAREZ seja primor de clareza e de coerência é ponto sobre o qual não pretendo insistir; mas é daqueles que nenhuma história da filosofia do direito pode negligenciar, porque, no extremo fim do século XVI e início do XVII, sua doutrina conclui a grande obra de Salamanca, e esta conheceu destino impressionante no mundo escolar: SUAREZ lega à Europa moderna o que esta acredita desde então ser o conteúdo da 'escolástica católica', o que esta desde então acredita ser o 'tomismo'." Ver tb. CHEVALIER, J. La pensée chrétienne. Paris: Flammarion, 1956; VINCENT, A. La notion de droit naturel et de volontarisme, de SUAREZ à ROUSSEAU. Paris: Archives de philosophie du droit, 1963. p. 237 ss.

8 Ver CASELlA, P. B. Direito internacional no tempo medieval e moderno até Vitoria. São Paulo: Atlas, 2012. esp. cap. XI, 'Tratadistas da guerra: Balthazar AYALA e Pierino BELLI', p. 245-379) para a evolução do tratamento da guerra, na transição entre o contexto medieval e o moderno. 
o fenômeno. Cada geração se coloca sobre os ombros das precedentes - e isso vale, tanto para usufruir as realizações, quanto para pagar pelos erros cometidos: uns e outros serão compartilhados. Se isso vale em todas as áreas do conhecimento, aplica-se muito especialmente no direito internacional. ${ }^{9}$

Suarez se inscreve no contexto da Espanha como potência dominante de seu tempo. ${ }^{10}$ Para situar a Espanha, como potência dominante da Europa, no início da era moderna, alguns marcos relevantes podem ser assinalados: no mesmo ano de 1492 se sobrepõem à expulsão dos 'mouros' de Granada, e com isso se completa a unificação territorial e política da Espanha moderna, e também no mesmo ano, ocorre o descobrimento da América, por Cristovão Colombo - enquanto no Brasil nos atemos ao ano de 1500, como marco comemorativo do descobrimento do Brasil por Pedro Álvares Cabral.

A conjugação dos descobrimentos, resultado das grandes navegações, leva ao estabelecimento de zonas de influência e de exploração colonial europeias em outros continentes. Isso se tentou regular de várias formas. Inicialmente foram, essas áreas de dominação colonial, estipuladas entre Bulas papais e, posteriormente, pelo tratado bilateral de Tordesilhas (1494). Aí se vê a mutação do sistema medieval (hierárquico e centralizado) para o moderno modelo interestatal, não hierarquizado.

O papa Alexandre VI [Borgia] reconhece e declara legítima a atuação colonial, desde que sob a desculpa de ser feita a conquista para a expansão e a defesa da fé. Muito embora se tenham cometido enormes excessos e devastações nesse processo de conquista colonial.

Para situar o contexto da época, vale lembrar ter ocorrido, de 1580 até 1640, estarem Portugal e Espanha em regime de união das coroas. Nesse contexto, o espanhol

9 No sentido da perspectiva histórica para o estudo e a compreensão do direito internacional, ver: NYS, Ernest. Les origines du droit international. Bruxelles: Alfred Chastaigne / Paris: Thorin \& Fils, 1894; GREWE, Wilhelm. Epochen der Völkerrechtsgeschichte. Baden-Baden: Nomos, 1984; onde este apontava, sucessivamente: o ius inter gentes da era hispànica (1494-1648), o droit public de l'Europe da era francesa (1648-1815), para se chegar ao international law da era britânica (1815-1919), o direito das gentes e a união dos povos (Völkerrecht und Völkerbund) no período entre guerras (1919-1944) e concluía o trabalho com o exame do direito internacional na era da confrontação americano-soviética e da ascensão do terceiro mundo (1945 até a publicação do livro, em 1984). Também relevantes as contribuições para o tema: NUSSBAUM, Arthur. A concise history of the law of nations. New York: Macmillan, 1954; KOSKENNIEMI, Martti. The gentle civilizer of nations: the rise and fall of international law (1870-1960) ("Hersch Lauterpacht Memorial Lectures". ${ }^{\text {st }}$. published 2001, reprinted 2005. Cambridge: University Press, 2005); bem como a recente e bastante abrangente obra coletiva, sob a coordenação de Bardo FASSBENDER e Anne PETERS (edited by, with Simone PETER and Daniel HÖGGER, assistant editors), The Oxford Handbook of the History of International Law (Oxford: Univ. Press, 2012, cit. p. 2) no qual advertem: "The Eurocentric story of international law has proven wrong because it is incomplete."

10 BELENGUER, Ernest. Historia de la España moderna: Desde los Reyes católicos hasta Felipe II. Madri: Gredos, 2011; GARCÍA DE CORTÁZAR, Fernando; GONZÁLEZ VESGA, José Manuel. Breve historia de España. Madri: Alianza, (C) 1994. (nueva ed., 2010; cap. XI, 'la monarquía universal', p. 228-322), bem como o clássico de BRAUDEL, Fernand. La méditerranée et le monde méditerranéen à l'époque de Philippe II 1949. 8. ed. Paris: Armand Colin, 1987. 2 v. 
Francisco Suarez foi nomeado pelo rei da Espanha para a cátedra de teologia em Coimbra, mas apesar disso, encontrou objeções para tomar posse de sua cátedra, apesar de já então ser considerado um dos maiores expoentes intelectuais do seu tempo. Dado que Coimbra suscitava objeções pela falta de título de doutor - Suarez obtém seu título em Évora e, a seguir, volta para assumir a cátedra, em Coimbra. As 'picuinhas' pessoais no meio universitário não datam de hoje, nem se encontram somente entre nós.

A lição da potência dominante nos mostra o período inicial da era moderna (1494-1648), marcado pela preponderância espanhola. Isso se vê não somente na Europa, mas também por suas projeções como potência mundial, das Américas à Ásia, no imenso «império onde o sol nunca se punha». Desse tempo, vê-se a importância decrescente do poder político e da estatura pessoal de seus sucessivos detentores: o imperador Carlos V suscita nossa admiração, o rei Felipe II nossa atenção, Felipe III nossa indiferença, Felipe IV nossa simpatia, e Carlos II nos dá pena - observava G. Marañon, na biografia do conde e duque de Olivares (1587-1645). ${ }^{11}$ Justamente Olivares foi o homem que exerceu o poder de 1621 a 1643, lança em 1636 a Espanha na «guerra dos trinta anos» e a levará à perda da sua posição hegemônica ao cabo do conflito.

Sobre Suarez advertia C. Barcia Trelles (1933), ${ }^{12}$ na Haia

A história nem sempre é objetiva, na sua medida dos valores. Circunstâncias de lugar e de tempo, de paixões políticas, inclinações religiosas, pesam no sentido de afastar a imparcialidade dos julgamentos emitidos. Isso aconteceu com Francisco SUAREZ. [...] Mas esses desvios qualitativos sempre têm o caráter episódico dos eclipses. Enfim, a luz se faz.

Na evolução do Direito Internacional, podem ser apontadas três tendências, no período:

- $\quad$ primeira, o fundamento objetivo ou natural do direito, antes universalmente admitido, tendência essa ilustrada pelos juristas teólogos como Vitória, Suarez e outros;

- $\quad$ segunda, concepção de 'direito natural', decorrente da razão humana, mesmo sem a base religiosa (abertamente assumida): em lugar de 'cristianismo' ou 'comunidade cristã' fala em 'civilização', e, entenda-se, sobretudo a civilização

11 MARAÑON, Gregorio. Olivares - der Niedergang Spaniens als Weltmacht (do original El Conde-Duque de Olivares - La pasión de mandar, s/d, übersetzt und eingeleitet von Ludwig PFANDL, München: Hermann Rinn, s/d, Published under Military Government Information Control License Nr. US-E-161); ver tb. SALLMANN, Jean-Michel. Charles Quint - L'empire éphémère (originalmente publicado em 2000, Paris: Payot Rivages, 2004)

12 BARCIA TRELLES, C. Francisco Suarez (1548-1617): les théologiens espagnols du XVI siècle et l'école moderne du droit international. Recueil des Cours de L'Académie de Droit International, t. 43, p. 385-554, 1933. 
europeia - abrangência e eficácia da ideia de 'comunidade cristã' bastante comprometidas depois da selvageria de décadas de guerras europeias de religião; e

- terceira, tendência positiva ou positivista, também chamada direito internacional 'prático' ou 'europeu' - na escola histórica, utilitarista, positivista, em sentido estrito, materialista, materialista histórica, sociológica, e esta predomina - sem sufocar completamente correntes opostas de pensamento, durante a maior parte do século XVIII e do século XIX, representada, por Gentili em Oxford - continuada por Zouch, seu sucessor na mesma cátedra. E também por outro inglês, Selden. ${ }^{13}$

Dentre as grandes transformações do mundo, ocorridas nesse período, interessa sobremodo para o direito internacional o fato de que o sistema, antes quase exclusivamente europeu ocidental, passa a se projetar e atuar também sobre outros continentes, como a América, a Ásia e a África. Sob o impacto da expansão europeia, modelos e conceitos europeus passam a circular em vários continentes, mas também são influenciados por componentes locais.

Na medida em que América e Europa interagem em meio às transformações do sistema internacional, cabe traçar:

- paralelo entre o século XVI e o século XIX: impacto da América sobre a Europa, e o sistema de direito internacional - dados transformadores do mundo até então existente;

- mundo se compõe de vasos comunicantes, interação entre altos e baixos, o que se passa de bom e de ruim em cada continente; as influências se espalham;

- descobertas da América (em 1492 e 1500): grande transformação do direito internacional medieval ao sistema moderno, com efeitos além do período;

- a América traz, novamente, elemento transformador, ao cabo do período: o processo de independência das antigas colônias europeias - algumas exceções, mas se pode considerar o conjunto - processos vão da independência dos Estados Unidos, 1776, ao conjunto das antigas colônias espanholas e portuguesa, entre 1810 e 1825 ;

- a partir dessa altura, o antigo sistema europeu de Direito Internacional, passa a ser europeu e americano: não foi o único, mas dado da grande transformação do mundo.

13 A respeito de GENTILI, ZOUCH e SELDEN ver CASELLA, Paulo Borba. Direito internacional no tempo moderno: de Suarez a Grócio e Pufendorf. São Paulo: Atlas, 2013. esp. caps. XVI e XVII. 
Ao apontar algumas lições básicas de Suarez, merece destaque a sua bela concepção da unidade intrínseca do gênero humano, com a daí decorrente necessidade de arcabouço normativo comum:

O gênero humano, embora dividido em povos e reinos diversos, não deixa de ter unidade, não somente específica, mas também, por assim dizer, política e moral (...) Por isso, cada estado soberano (...) completo em si mesmo e firmemente estabelecido, ao mesmo tempo, não deixa de ser parte desse universo, no que concerne ao gênero humano. ${ }^{14}$

A respeito da linha divisória entre o direito natural e o direito das gentes, é igualmente de grande beleza a formulação de Suarez. Assim, ao fazer a linha divisória entre direito natural e direito das gentes, este anunciava a necessidade de conjunto de normas e princípios. Em razão da interdependência entre os povos, existe o direito internacional: porque este é necessário para a vida e a interação entre as coletividades humanas.

Suarez fala em direito das gentes, que convém à natureza humana, não por si e de modo absoluto, mas enquanto coletividade organizada politicamente

- $\quad$ Suarez, De Legibus (II.XIX.8): diga-se assim do direito das gentes: de modo único, é direito que todos os povos e coletividades devem aplicar entre si; de outro modo, que é direito que as cidades e reinos observam em seus âmbitos internos, que em razão de similitude e conveniência se chama de direito das gentes. ${ }^{15}$

- $\quad$ Suarez, De Legibus (II.XIX.10): em razão da conveniência das sociedades e seus fins próximos, como meio de comunicação de todas as nações entre si. ${ }^{16}$

- Suarez, De Legibus (II.XVIII.1): é necessário o direito das gentes, como convém à natureza humana, constituída em comunidades civis, pois muitas são as utilidades dos homens, que vivem em comunidades, que não dizem somente respeito à comodidade da natureza humana. ${ }^{17}$

14 SUAREZ, Francisco. De legibus ac Deo legislatore (1612; Lib. II, caput XIX, "Utrum jus gentium distinguatur à naturali tanquam simpliciter positium humanum", n. 9).

15 SUAREZ, De Legibus (II.XIX.8): "dici aliquid de iure gentium: uno modo quia est ius, quod omnes populi et gentes variae inter se servare debent; alio modo quia est ius, quod singulae civitates vel regna intra se observant, per similitudinem autem et convenientiam ius gentium appellatur."

16 SUAREZ, De Legibus (II.XIX.10): "pro fine proximo convenientem societatem, communicationem omnium nationum inter se."

17 SUAREZ, De Legibus (II.XVIII.1): “ad ius gentium necessarium esse, ut conveniat humanae naturae non absolute spectatae, sed ut iam constitutae in civili communitate, quia multa sunt utilia hominibus, ut in communitate viventibus, quae absolute non pertinent ad commodum naturae secundum se". E prosseguia, na mesma passagem: "Illa ergo quae conceduntur hominibus in communitate viventibus propter communem utilitatem, tamquam honesta, et non tamquam necessaria ad honestatem, nec tamquam praecepta, dicuntur esse de iure gentium." 
Em suma, algumas ideias centrais podem ser destacadas, à guisa de conclusão. A atuação de Suarez abrangeu vários campos, além de sua contribuição específica para o direito internacional moderno: foi ele aclamado como jurista e canonista, como teólogo, filósofo e autor de sistema de alcance quase enciclopédico, por seu tratado sobre As Leis e Deus legislador (Coimbra, 1612). Além de professor de grande renome, que ensinou filosofia e teologia nas melhores universidades europeias de seu tempo, tais como Alcalá, Madri, Roma, Salamanca, Coimbra e Paris.

Vale, ademais, ressaltar ter sido Suarez personagem que em época alguma da história, deixou de suscitar interesse. Isso mesmo se em diferentes épocas o valor a ele atribuído não foi idêntico em suas dimensões: Suarez não encontrou defensores, mas juízes severos, e estes nem sempre agiram de modo sereno.

As concepções jurídicas de Suarez tiveram enorme repercussão e desdobramento não somente em sua época, mas também se projetam sobre os séculos seguintes. Interessam, ainda, para o conhecimento das concepções jurídicas de Suarez. ${ }^{18}$

Em suma, é preciso situar Suarez no seu tempo e também por suas projeções, além daquela época, até nossos tempos pós-modernos: foi ele um dos mais ilustres autores da ordem dos jesuítas - e pelo seu engajamento na defesa da "fé católica e apostólica" foi exornado com o título de doctor eximius, pelo então papa, Bento XIV.

Seria, este, assim prosseguimento, e mais um capítulo da longa querela medieval sobre a primazia temporal entre o papado e o imperador e os reis, que se prolonga pela Idade moderna? Em contexto, ademais, agravado pela cisão e confrontação entre protestantes e católicos, entre os quais se dilacerava a Europa 'moderna'.

Assim como Francisco de Vitória (1480-1546), foi Suarez personalidade marcante, e relevante referência intelectual do tempo. Ele se viu engajado nos debates da época.

A obra de Suarez se pautou por fins práticos: no contexto de seu tempo, os teólogos tinham dentre as suas principais atribuições, o papel de diretores de consciência, e orientação de conduta, inclusive dos soberanos, e isto não somente em relação ao âmbito

18 Sua obra abrange outros escritos: seu estudo sobre “a justiça de Deus"; suas obras filosóficas, contendo comentários sobre diversas obras de Aristóteles; sua famosa obra de metafísica, Disputationes metaphysicae; suas obras como polemista na defesa da fé, Defensio fidei catholicae et apostolicae adversus Anglicanae sectae errores (Coimbra, 1613) dirigida "contra os erros da seita anglicana", contra o rei da Inglaterra, James I; suas obras de direito canônico, De censuris - sobre as penas eclesiásticas; bem como a obra sobre as imunidades eclesiásticas, De immunitate ecclesiae; e, finalmente; seus Consilia, ou 'conselhos', nos quais se volta para questões jurídicas, morais etc.; o tratado sobre as virtudes teologais Opus de triplice virtute theologica: Fides, Spe \& Charitate, in tres tractatus pro ipsarum virtutum numerum distributum (Coimbra, 1621) - fé, esperança e caridade - "Disputatio" XVIII do tratado sobre a Fé, sobre "meios que podem ser usados para a conversão e coerção dos infieis que não sejam apóstatas", e a "Disputatio" XIII do tratado sobre a caridade, De charitate, "sobre a guerra" (de bello) - que contém relevante lição sobre o direito da guerra. 
pessoal e moral individual, mas abrangia, também, a atuação pública destes: daí o papel dos consilia, ou pareceres, para nortear a ação prática, e as políticas de estado.

E para o situar também no nosso contexto pós-moderno, e na perspectiva do diálogo com as fontes, podemos ver:

- $\quad$ em Suarez, a presença da herança histórica, de Tomás de Aquino a Vitória, mas também existe inovação;

- para Vitória o Direito Internacional parecia resultar do direito natural de comunicação entre os homens (jus communicationis); para Suarez o Direito Internacional se constrói entre os homens: é necessidade decorrente da conjugação entre convivência e divisão em reinos e repúblicas

- Suarez inova ao considerar o gênero humano, apesar de dividido em povos e reinos, não deixa de ter e ser também uma unidade. Esta constitui o fundamento da "comunidade internacional".

Este breve exame do conjunto da vida e da obra deste internacionalista espanhol do início da era moderna nos traz relevante contribuição. Que muitas vezes é pouco lembrada, mas nem por isso menos oportuna e necessária, para a compreensão do conjunto da evolução do direito internacional até os nossos tempos.

São Paulo, Janeiro de 2012. 